The analysis of the proper-motions of 20,843 stars, derived from the Cape astrographic plates, was of special importance to stellar statistics, because of their wide range in galactic latitude. Under his directorship the Cape Observatory has undertaken an extensive programme of stellar photometry, providing for the first time photographic and photovisual magnitudes of high accuracy of many stars in the southern sky. Dr. Jackson has been president of the Commission on Meridian Astronomy of the International Astronomical Union, and is now president of the Commission on Steller Parallaxes and Proper Motions.

Dr. R. H. Stoy

Dr. R. H. Sroy, who succeeds Dr. Jackson and so becomes the ninth H.M. Astronomer at the Cape, has been chief assistant at the Royal Observatory, Cape of Good Hope, since 1935. Born at Wolverhampton and educated at King Edward VII School, Birmingham, he went to Gonville and Caius College, Cambridge, to continue his mathematical studies. From an early age he had been interested in astronomy and he continued to work on this subject. After taking his degree, he was awarded a Commonwealth Fellowship and went to the Lick Observatory, where he spent the years 1933-35. He investigated problems connected with the spectra of nebulæ, for which work he was awarded a Ph.D. degree at Cambridge. His interest in practical astronomy made him an ideal astronomer for the Cape Observatory, where he went on returning from the United States. At the Cape he found that a large programme of work had been started to determine the positions and magnitudes of stars down to the ninth magnitude south of dec. $-30^{\circ}$. For the positionel work the necessary framework was already available, and it was hoped to determine the brightness of the stars by means of standards at declination $-45^{\circ}$. Dr. Stoy soon found that the standards available were not sufficiently accurate, and a great deal of his time during the prost ten years has been concerned with the setting up of accurate standards at declination $-45^{\circ}$ for both photographic and visual magnitudes, and connecting them with the best standards in the sky north of the equator visible from South Africa. In this work he collaborated with Prof. R. O. Redman, now director of the Cambridge Observatories, but working at the Radcliffe, Observatory, Pretoria, until 1947.

\section{Voyage of the Royal Research Ship William Scoresby, 1950}

The Royal Research Ship William Scoresby recently arrived in Plymouth after a ten-month voyage of research on oceanography and whales in South African waters. This veteran research ship was built twenty-four years ago for the Discovery Committee and is equipped for general oceanographical work, trawling and marking of whales. The voyage has been a continuation of the Discovery Investigations, and the whole work is controlled by the National Institute of Oceanography (see Nature, January 21, p. 105). The principal items of research during the voyage were surveys of the Benguela Current off South-West Africa at two different times of year, and whale marking and a short survey of the Agulhas Current in south-east African waters. The investigations of the Benguela Current included a series of observations on the physical, chemical and biologicel features of the waters, carried out during the first part of the voyage and then repeated during September-October. In this region, cold water wells up from the ocean depths, bringing nutrient salts to the surface and thereby stimulating the growth of marine life. But, in spite of the rich marine life, the sea floor in this locality is remarkable for a considerable area of sterile mud conteining hydrogen sulphide, and the researches of the expedition should add considerably to present knowledge of the extent of the sterile region. It has been suggested that the deposit of organic debris which takes place in such 'azoic' muds is connected with the formation of oil deposits. The whales marked in the south-east African region and at various other points in the voyage included a high proportion of sperm whales, a species the habits of which are little known, and this part of the work is the first occasion on which any substantial numbers of whales have been marked in tropical and subtropical waters. During most of the voyage, Mr. R. Clarke was in charge of the scientific work, assisted by Mr. R. I. Currie.

\section{Modern Developments in Radio Engineering}

IN his presidential address to the British Institution of Radio Engineers on September 27, Mr. P. Adorian pointed out that during the coming year the Institution will be celebrating its twenty-fifth anniversary and that plans are being made to hold a convention to cover many fields of radio engineering. $\mathrm{H}_{\theta}$ then gave a brief survey of achievements in recent years in radio engineering with an indication of possible future developments, particularly in matters concerning industrial electronics, aeronautics and broadcasting. Mr. Adorian emphasized that, while radio engincers seem to appreciate that numerous production and operation methods could be made more efficient by the use of electronic techniques, it is surprising to find how little of this knowledge is applied in practice in industry and in medical science. In the field of aeronautics, while modern air transport would be impossible without radio communication and naviga. tional aids, there seems to be a need for speeding up and simplifying signalling methods to keep pace with the steadily increasing speed of modern aircraft.

After reviewing the progress of broadcasting towards the ideal of providing a satisfactory service in all populated areas of the world, Mr. Adorian referred briefly to a relatively new method of using short-wave radio for the provision of a local service. Basically, the system consists of high-frequency transmitters with aerials which radiate mainly in a vertical direction, giving relatively short-range reflexions from the ionosphere. The first of these systems began operating in India several years ago; in 1947 Radio Trinidad started to broadcast on this principle on a wave-length of $30 \mathrm{~m}$. (10 Mc./s.), while last July a station of the same type was installed in Jamaica, using a wave-length of $60 \mathrm{~m}$. (5 Mc./s.). Local reception is satisfactory during daylight; but at night interference is experienced with the transmissions from distant high-power stations operating on the same frequencies.

\section{Biology and Control of Pharaoh's Ant}

THE most familiar ant in houses in Great Britain is the common black ant Lasius niger, but a much more serious pest when it occurs is the tiny insect known as Pharaoh's ant, Monomorium pharaonis (L.), which measures less than three millimetres in length. A monograph by Prof. A. D. Peacock and others, recently published by the Department of Agriculture for Scotland (Misc. Pub. No. 17; pp. 